\title{
Tiras em quadrinhos e cartuns: a divulgação de informações em saúde num jornal universitário
}

\author{
Carlos Teixeira ${ }^{1}$ \\ Escola de Comunicações e Artes da Universidade de São Paulo
}

DOI:

\begin{abstract}
Resumo
Objetivo: discorre acerca da veiculação de tiras de histórias em quadrinhos e cartuns utilizados na transmissão de informações de divulgação científica em saúde. Método: foram analisados os 56 episódios tiras de histórias em quadrinhos e cartuns veiculados pelo Jornal da Paulista, jornal universitário da Universidade Federal de São Paulo/Escola Paulista de Medicina, que circulou entre os anos de 1987 a 2003. Resultados: constatou-se a ocorrência de 12 tiras em quadrinhos e 31 cartuns que abordavam informações de saúde e 13 cartuns que abordavam outros temas. A consulta em bibliografia específica possibilitou constatar o emprego desses recursos no campo da saúde. Conclusões: a literatura quadrinistica não é mais vista como marginal ou apenas como objeto de entretenimento, mas tem um uso efetivo para a divulgação de informações, bem como a possibilidade de divulgar a ciência produzida em diferentes campos do conhecimento, entre eles o da saúde. Palavras chave: Cartum. Histórias em quadrinhos. Promoção da Saúde. Comunicação e Divulgação Científica.
\end{abstract}

\section{Resúmen}

Objectivo: habla de la publicación de historietas y cartoons utilizados en la transmisión de información científica en salud. Método: se analizaron los 56 episodios de historietas y cartoons publicados por Jornal da Paulista, el periódico de la Universidade Federal de São Paulo/Escola Paulista de Medicina, publicado entre los años de 1987 a 2003. Resultados: se observó la ocurrencia de 12 historietas y 31 cartoons que abordan información de la salud y 13 cartoons que abordan otros temas. La investigación bibliográfica consultada con el objetivo de comprender el fenómeno del uso de historietas y cartoons para divulgación de información reveló un uso para la difusión de diferentes tipos de información, incluyendo la que señaló para este artículo, la difusión de la ciencia. Conclusiones: la literatura quadrinística ya no es vista como marginal o solamente como un objeto de entretenimiento, pero ha producido una utilización eficaz de difusión de información, asi como la posibilidad de difundir la ciencia en diversos campos del conocimiento, incluida la salud.

Palabras-clave: Cartuns. Historietas. Promoción de la salud. Comunicación y popularización de la ciéncia.

\footnotetext{
Abstract

Objective: talks about the publication of comic strips and cartoons used for the transmission of scientific information in health. Method: we analyzed the 56 episodes of comics and cartoons published by Jornal da Paulista, the newspaper of the University of São Paulo,

1 Doutor em Ciências pela Faculdade de Saúde Pública da Univesidade de São Paulo. Pósdoutorando no Departamento de Informação e Cultura da Escola de Comunicações e Artes da Universidade de São Paulo. Email: cteixeira@usp.br. ORCiD:
} 
Universidade Federal de São Paulo/Escola Paulista de Medicina, which circulated from 1987 to 2003. Results: we observed the occurrence of 12 comic strips and 31 cartoons that addressed health information and 13 cartoons that addressed other topics. The bibliographical research aimed to understand the phenomenon of the use of cartoons and comics for dissemination of information; it revealed a use for the dissemination of different kinds of information including that mentioned in this article, the dissemination of science. The query on specific bibliography enabled the employment of these resources in the field of health. Conclusions: the comics literature is no longer seen as marginal or only as an object of entertainment, but it has an effective use towards the dissemination of information, as well as the possibility to disseminate the science produced in different fields of knowledge, including health.

Keywords: Cartoons. Comics. Health Promotion. Public Communication of Science.

\section{Introdução}

A Escola Paulista de Medicina (EPM), criada em 1933 e federalizada em 1956, foi elevada à condição de universidade no ano de 1994. Contudo, foi apenas no ano de 2003 já como Universidade Federal de São Paulo (UNIFESP) que se iniciou o processo de expansão para outras áreas do conhecimento que não apenas a da Saúde. Até então se mantinha a tradição histórica de uma instituição voltada às atividades científicas e educacionais suplementares ao trabalho médico, ligadas à faculdade de Medicina (SILVA, 2001), e às faculdades de Biomedicina, Enfermagem, Fonoaudiologia e Ortóptica (PUCCINI, SAMPAIO, BATISTA, 2008).

No mês de novembro de 1987 a EPM lançou a primeira edição do Jornal da Paulista, jornal universitário que circulou até dezembro de 2003. Pelas características específicas da instituição à qual representava, o Jornal da Paulista foi o único jornal, em sua categoria, totalmente dedicado à divulgação de informações no campo das ciências da saúde.

Por algumas edições, entre os anos de 1989 a 1999, foi veiculada no Jornal da Paulista uma série de tiras em quadrinhos e cartuns. Esses materiais não foram objeto de um estudo de análise de conteúdo propriamente dito, contudo, são apresentados neste artigo os resultados da análise dos mesmos como documentos portadores de informações, especificamente como documentos de divulgação cientifica em saúde, que objetivavam uma aproximação com o público leigo, utilizando o recurso do humor, uma das características específicas das histórias em quadrinhos e cartuns (MAGALHÃES, 2006). A particularidade dos documentos 
coletados, por conterem em sua maioria informações do campo da saúde, constituiu-se em si o foco de atenção e de análise deste artigo.

O artista plástico, Sthar-Mar de Vasconcelos, autor de todas as tiras em quadrinhos e cartuns publicados no Jornal da Paulista, ao tratar acerca da veiculação de quadrinhos nesse jornal universitário, declarou em entrevista publicada na coluna "Artistas da Casa", (Jornal da Paulista, n. 56 - nov. 1992), que os mesmos "são um importante instrumento de comunicação. A mensagem é passada de maneira mais completa, através da literatura da imagem".

Reconhecendo a relevância dos quadrinhos para a divulgação de informações de ciência no geral, e particularmente para o campo da saúde, e não apenas como forma de entretenimento, apresentamos neste artigo uma reflexão sobre essa temática. São também apresentados os resultados da pesquisa acerca das tiras em quadrinhos e cartuns que foram veiculadas no Jornal da Paulista.

Como ponto de partida para o estudo das histórias em quadrinhos e cartuns veiculados no Jornal da Paulista, destaca-se a definição do American Heritage Dictionary of the English Language (Disponivel Online, tradução nossa), segundo o qual cartum, ou quadrinho, é "um desenho retratando uma situação engraçada, muitas vezes acompanhada por uma legenda" e história em quadrinhos é "uma seqüência narrativa, geralmente bem-humorada de cartuns"2 ${ }^{2}$ Portanto, um cartum é ao mesmo tempo um quadrinho e uma história em quadrinhos é uma sequência de quadrinhos. No Jornal da Paulista, ambas representações se fizeram presentes, conquanto a veiculação de cartuns foi quase quatro vezes superior à veiculação de histórias em quadrinhos.

Cabe ressaltar que uma história em quadrinhos pode conter um único quadrinho, "desde que, consiga representar um movimento, narrar um fato, contar uma história" (GUIMARÃES, 2010, p. 31), como retratado na figura 1, a seguir:

2 Cartoon: "A drawing depicting a humorous situation, often accompanied by a captio". Comic Strip: "A usually humorous narrative sequence of cartoon panels". 
Figura 1 - Tira de quadrinhos de Bob Thaves, utilizando um único quadrinho

Frank \& Ernest Bob Thaves

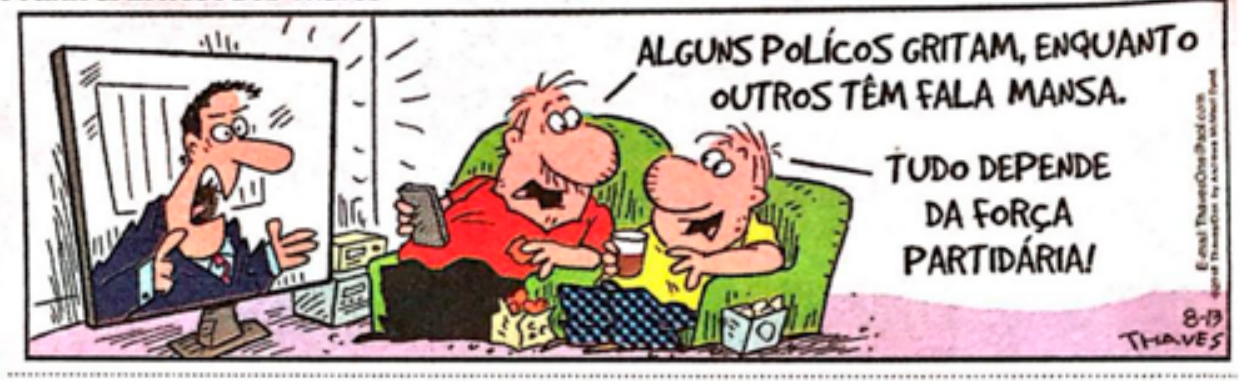

Fonte: O Estado de São Paulo, Caderno 2, C4, 13 ago. 2018. Acervo do autor.

Há outras definições, consideradas mais apropriadas para as histórias em quadrinhos. Entre os estudiosos do tema, Will Eisner, ao mesmo tempo um dos mais importantes autores de histórias em quadrinhos, emprega o termo "Arte Sequencial" para definir as histórias em quadrinhos. Segundo ele, os quadrinhos são "uma forma artística e literária que lida com a disposição de figuras ou imagens e palavras para narrar uma história ou dramatizar uma ideia". Para ele, "as histórias em quadrinhos apresentam uma sobreposição de palavra e imagem, e, assim, é preciso que o leitor exerça as suas habilidades interpretativas visuais e verbais" (EISNER, 2010, p. 92).

Já para Scott McCloud, outro ícone dos estudos acerca da linguagem das histórias em quadrinhos, elas são "destinadas a transmitir informações e/ou a produzir uma resposta no espectador" (McCLOUD, 1995), uma vez que quadrinhos são imagens organizadas propositalmente de maneira justapostas com um determinado objetivo narrativo (BRANDÃO, 2018).

A definição mais abrangente é de Brandão (2018), para quem as histórias em quadrinhos são consideradas uma mídia, na qual "cabem todos os gêneros e os mais diversos temas". São reconhecidas por ele como "uma forma de comunicação muito rica que pode ser usada para entreter, informar e, também, educar". Além disso, "os assuntos tratados nos quadrinhos podem ter a leveza e a ludicidade que encantam crianças e adolescentes, mas também podem mergulhar na densidade de temáticas adultas e complexas" (BRANDÃO, 2018). 


\section{1 - Material e Método}

Lakatos e Marconi (2006, p. 175) discorrem sobre a possibilidade de diferentes técnicas serem empregadas pela ciência para buscar seus propósitos préestabelecidos, e Godoy (1995, p. 21) propõe três diferentes abordagens para a pesquisa qualitativa: a pesquisa documental, o estudo de caso e a etnografia.

A pesquisa relatada neste artigo foi orientada pelos principios fundamentais da pesquisa documental. Para Gil (2007) embora existam semelhanças entre a pesquisa documental e a bibliográfica, na essência a diferença entre ambas está na natureza das fontes:

enquanto a pesquisa bibliográfica se utiliza fundamentalmente das contribuições dos diversos autores sobre determinado assunto, a pesquisa documental vale-se de materiais que não receberam ainda um tratamento analítico (GIL, 2007, p. 45).

A constatação da veiculação no Jornal da Paulista de histórias em quadrinhos e cartuns que divulgavam informações relacionadas a temas de saúde deu-se durante o processo da pesquisa qualitativa e descritiva da qual esse jornal foi o objeto de estudo, no programa de mestrado realizado no Centro de Desenvolvimento do Ensino Superior em Saúde (CEDESS) da Universidade Federal de São Paulo, cujos resultados estão disponiveis em Teixeira (2009). Contudo, naquele estudo as histórias em quadrinhos e os cartuns não foram incluídos como dados de análise como apresentado aqui neste artigo. Naquela ocasião, constou no relatório da pesquisa de mestrado apenas a referência de que foi veiculado pelo Jornal da Paulista uma série de histórias em quadrinhos e cartuns, inseridos numa sessão que algumas vezes recebeu o título de "A Hora do Recreio", sendo que na maioria das vezes as inserções eram feitas de forma aleatória.

Durante essa mesma pesquisa de mestrado, anteriormente referida, foram analisadas as 185 edições do JORNAL DA PAULISTA, publicadas entre $1987 \mathrm{e}$ 2003. Os dados que seguem foram retirados do banco de dados elaborado para analisar o Jornal da Paulista. Nesse banco de dados constam 12 histórias em quadrinhos e 44 cartuns, perfazendo um total de 56 episódios quadrinísticos veiculados em 32 edições do Jornal da Paulista (números 22 a 138), publicadas 
entre agosto de 1989 a dezembro de 1999. Contudo, ressalta-se é apenas para a produção deste artigo que esse material recebe um tratamento analítico, posterior à conclusão e publicação do relatório da pesquisa de mestrado.

A análise das tiras e cartuns veiculados no Jornal da Paulista possibilitou englobá-los em duas categorias: uma que versava especificamente sobre saúde e outra cujo conteúdo abordava temas diversos, incluindo temas correlatos à saúde, área de concentração da UNIFESP-EPM na ocasião de publicação e circulação do jornal.

O conteúdo das tiras e cartuns foi classificado de acordo com os registros icônico-textuais atribuidos pelo próprio autor-desenhista e jornal. Foram criadas três tabelas com o material coletado, duas delas discriminando as especificidades dos temas abordados nas categorias saúde e diversa, e uma apresentando dados quantitativos, que são apresentadas na sequência.

\subsection{Cartum como um descritor}

Considerando que os quadrinhos veiculados no Jornal da Paulista, tanto na forma de tiras como no formato de cartuns, traziam majoritariamente conteúdo informacional relacionado à temática de saúde, decidiu-se fazer uma busca acerca da possivel apropriação da linguagem dos quadrinhos por parte de pesquisadores, em específico os do campo da saúde, quer no formato de cartuns ou de história em quadrinhos (tira, página em quadrinhos, etc.), como recurso auxiliar para a transmissão/divulgação de informações.

O primeiro passo dessa busca consistiu em consulta, a última delas atualizada em 30 de outubro de 2018, nas Bases de Dados, SciELO em português e PubMed em inglês, sendo esta última específica para recuperação de publicações no campo das ciências da saúde. Buscou-se em primeiro lugar verificar a existência de algum descritor, particularmente em ciências da saúde, associado à temática que pudesse auxiliar na recuperação bibliográfica de documentos, em específico artigos, que abordassem os temas quadrinho(s), cartum(ns) e história(s) em quadrinho(s).

Por definição descritor consiste num vocabulário estruturado ou controlado que possibilita a pesquisa em artigos indexados em base de dados. No caso da base de dados PubMed, os descritores são definidos pelo Medical Subject Heading 
Terms (MeSH). A consulta no MeSH Terms revelou que a pesquisa na PubMed poderia ser realizada utilizando como descritor o termo Cartoon as Topic.

Utilizando esse descritor foi possivel recuperar 945 documentos indexados na base de dados PubMed. Já na base dados SciELO, embora não tendo descritor especifico para o tema em questão, foi possivel a recuperação de 52 documentos empregando os termos não estruturados "Quadrinhos" e nove documentos utilizando "Histórias em Quadrinhos", sendo que esses nove documentos estão também incluidos na lista dos 52 artigos recuperados utilizando o termo "Quadrinhos".

A constatação da indexação em Base de Dados de artigos abordando a temática de cartuns e histórias em quadrinhos, subsidia a concepção da relevância do estudo desse material com perspectiva de se teorizar sobre sua contribuição dentro do campo científico, contudo, essa análise não é objeto deste artigo.

\section{2 - Resultados}

Do total das 56 inserções quadrinisticas no Jornal da Paulista, 12 foram registros de histórias em quadrinhos e 44 registros de cartuns. Das 56 inserções, a totalidade das 12 tiras em quadrinhos e 31 cartuns, correspondendo 43 registros e a $78,6 \%$ de todo o material publicado no Jornal da Paulista, estavam diretamente relacionados ao tema saúde. Os $21,4 \%$ restantes correspondem aos 13 cartuns inseridos na categoria não saúde, ou outra.

Das 12 tiras publicadas no Jornal da Paulista, apenas uma delas não abordava diretamente um tema de saúde, embora houvesse uma correlação ao contexto por abordar acerca da informática aplicada à cirurgia, uma área de estudo da então UNIFESP-EPM.

Oito temas diferentes de saúde foram objeto do enredo das tiras. Três delas abordaram o tema câncer de mama e duas abordaram o tema insônia. Os demais temas, colesterol, moléstia de Ménière, catapora, AIDS, fecundação, infecção hospitalar e informática aplicada à cirurgia foram abordados, cada um deles, em apenas uma tira em quadrinhos.

Dos 44 cartuns publicados no Jornal da Paulista, 31 abordavam diretamente o tema saúde. Com exceção dos temas câncer, fumo e nutrição que tiveram, 
respectivamente, a incidência de três inserções o primeiro e duas inserções o segundo e o terceiro, todos os demais temas foram abordados em um cartum cada um deles.

Os cartuns abordaram também os seguintes temas: cólera, higiene, hanseníase, virus, comércio irregular de medicamento, moléstias parasitárias, drogas, fitoterapia, labirintite, cólicas, ronco, cirurgia plástica, transplante/doação de órgãos, malefícios do sol, coluna, catarata, reciclagem de lixo, adolescência e violência, lúpus, estresse, ansiedade, epilepsia e esporte, ginecologia, e bulimia.

A tabela a seguir apresenta os temas de saúde que foram abordados nas tiras e cartuns veiculados pelo Jornal da Paulista. O tema predominante foi câncer com seis inserções, três tiras e três cartuns, seguido do tema insônia, duas do tema fumo, além de dois cartuns, e, do tema nutrição, também dois cartuns. Os demais temas de saúde foram abordados uma única vez tanto nas tiras quanto nos cartuns.

Tabela 1: Tiras em quadrinhos e cartuns categoria saúde veiculados no Jornal da Paulista no periodo de 1989-1999.

\begin{tabular}{|c|c|c|}
\hline Assunto & $\begin{array}{c}\text { Tiras em } \\
\text { quadrinhos }\end{array}$ & Cartuns \\
\hline Câncer & 3 & 3 \\
\hline Insônia & 2 & \\
\hline Colesterol & 1 & \\
\hline Moléstia de Ménière/Labirinto & 1 & 1 \\
\hline Catapora & 1 & \\
\hline AIDS & 1 & \\
\hline Fecundação & 1 & \\
\hline Infecção Hospitalar & 1 & \\
\hline Informática aplicada à cirurgia & 1 & \\
\hline Cólera & & 1 \\
\hline Fumo & & 2 \\
\hline Sol - Problemas & & 1 \\
\hline Higiene & & 1 \\
\hline Hanseníase & & 1 \\
\hline Medicamentos & & 1 \\
\hline Moléstias Parasitárias & & 1 \\
\hline Drogas & & 1 \\
\hline Fitoterapia & & 1 \\
\hline Cólica & & 1 \\
\hline Ronco & & 1 \\
\hline Cirurgia Plástica & & 1 \\
\hline Transplante de órgãos & & 1 \\
\hline Coluna & & 1 \\
\hline Catarata & & 1 \\
\hline Reciclagem de Lixo & & 1 \\
\hline Adolescência e Violência & & 1 \\
\hline
\end{tabular}




\begin{tabular}{|cc|}
\hline Nutrição & 2 \\
\hline Lupus & 1 \\
\hline Estresse & 1 \\
Ansiedade & 1 \\
Epilepsia e Esporte & 1 \\
Ginecologia & 1 \\
Virus & 1 \\
\hline Bulimia & 1 \\
\hline TOTAL & \\
\hline
\end{tabular}

As quarenta e três ocorrências, composta de tiras em quadrinhos (12) e cartuns (23), abordando o tema saúde, aconteceram durante um periodo de oito anos de circulação do Jornal da Paulista. Conforme pode ser constatado na tabela a seguir, as inserções ocorreram de forma sistemática entre os anos de 1989 a 1995, sofrendo uma interrupção até voltarem a ser publicadas no ano de 1999 , ano no qual foram publicados os últimos registros quadrinisticos, correspondendo a quatro cartuns. A partir de 1999, até o encerramento de sua circulação em 2003, o Jornal da Paulista não publicou mais nenhuma tira em quadrinhos ou cartum.

Os oito anos durante os quais foram publicadas tiras e cartuns no Jornal da Paulista, correspondem a 93 edições do jornal. Três edições do jornal nesse periodo foram publicações bi-mensais. Nesse mesmo período $34,4 \%$ do total dessas edições foram publicadas com pelo menos uma inserção de tira e/ou cartum. Essas inserções não ocorreram de forma sistemática e sequencial mês a mês. Na média havia a inserção de pelo menos uma tira em quadrinhos ou um cartum a cada 1,7 edição publicada do jornal.

O total das 56 ocorrências tiras e cartuns foram assim distribuídas ao longo dos oito anos: 1989: cinco; 1990: sete; 1991: duas; 1992: 10; 1993: 18; 1994: cinco; 1995: cinco e 1999: quatro ocorrências.

A ocorrência de tiras e/ou cartum por edição do Jornal da Paulista foi, também, distribuida na ordem de maior incidência: cinco ocorrências na edição número 58 (outubro de 1992); cinco na edição número 68 (agosto/setembro de 1993); quatro na edição 59 (novembro de 1992); três nas edições 69, 70 e 81 (outubro de 1993, novembro de 1993 e janeiro de 1995); duas nas edições 62, 67, 71, 78 e 82 (março de 1990, fevereiro de 1993, julho de 1993, dezembro de 1993, março de 1994 e fevereiro de 1995) e nas demais edições apenas uma ocorrência.

Essa distribuição pode ser percebida na tabela 2, apresentada a seguir. 
Tabela 2: Inserções de tiras em quadrinhos e cartuns veiculadas no JORNAL DA PAULISTA (1989-1999) - 93 edições.

\begin{tabular}{|c|c|c|c|c|c|c|c|}
\hline \multicolumn{6}{|c|}{ INSERÇóES } & \multirow{2}{*}{\multicolumn{2}{|c|}{$\begin{array}{c}\text { TOTAL } \\
\text { Cartuns + } \\
\text { histórias em } \\
\text { quadrinhos }\end{array}$}} \\
\hline Ano & \multicolumn{2}{|c|}{$\begin{array}{l}\text { Histórias em } \\
\text { quadrinhos }\end{array}$} & \multicolumn{3}{|c|}{ Cartuns } & & \\
\hline & $\mathrm{N}$ & $\% / 56$ & $\mathrm{~N}$ & $\mathrm{~N}^{*}$ & $\% / 56$ & $\mathrm{~N}$ & $\% / 56$ \\
\hline 1989 & 5 & 8,9 & & & - & 5 & 8,9 \\
\hline 1990 & 3 & 5,4 & 1 & 3 & 7,1 & 7 & 12,5 \\
\hline 1991 & - & - & & & 3,6 & 2 & 3,6 \\
\hline 1992 & 2 & 3,6 & 3 & 5 & 14,3 & 10 & 17,9 \\
\hline 1993 & 1 & 1,8 & 12 & 5 & 30,4 & 18 & 32,2 \\
\hline 1994 & 1 & 1,8 & 4 & & 7,1 & 5 & 8,9 \\
\hline 1995 & - & - & 5 & & 8,9 & 5 & 8,9 \\
\hline 1999 & - & - & 4 & & 7,1 & 4 & 7,1 \\
\hline Total & 12 & 21,7 & 31 & 13 & 78,3 & 56 & 100 \\
\hline
\end{tabular}

Embora as tiras em quadrinhos, em sua totalidade, abordassem temas de saúde, o mesmo não ocorreu com os cartuns. Dos 44 cartuns veiculados no Jornal da Paulista, 13 deles foram incluídos na categoria não saúde ou outra. Em termos percentuais esse grupo de cartuns corresponde a $23,2 \%$ de todo o material quadrinístico veiculado nesse jornal. Conquanto esse material tenha sido incluido na categoria não saúde como pode ser observado na tabela apresentada a seguir, ainda assim, indiretamente, os temas desses cartuns estão relacionados ao contexto dos cursos da área da saúde, área de concentração, como já referido, da UNIFESP-EPM por ocasião da publicação e veiculação do Jornal da Paulista.

Tabela 3: Cartuns, categoria não saúde, veiculado no Jornal da Paulista no periodo de 1989 a 1999.

\begin{tabular}{ccc}
\hline $\mathbf{N}$ & Edição/Ano & Assunto \\
\hline 1 & $28 / 1990$ & Exame para os médicos \\
2 & $29 / 1990$ & I Semana Literária EPM \\
3 & $33 / 1990$ & Simbolo da EPM (cobra e Jequitibá) \\
4 & $57 / 1992$ & Jubileu 5a turma (1942) \\
5 & $58 / 1992$ & Os emblemas da EPM/histórias \\
6 & $58 / 1992$ & O emblema da EPM/significado \\
7 & $59 / 1992$ & Logosofia/pessimismo \\
8 & $59 / 1992$ & Maratona dos 60 anos da EPM \\
9 & $65 / 1993$ & Os deuses da medicina/Festa EPM \\
10 & $7 / 1993$ & História da medicina \\
11 & $68 / 1993$ & Biblac/informatização \\
12 & $70 / 1993$ & Biblac/história \\
13 & $70 / 1993$ & História da medicina \\
\hline
\end{tabular}




\section{3 - Discussão}

Levando em consideração que os recursos visuais estão cada vez mais presentes como forma de divulgação da informação cientifica, optou-se pela análise dessas tiras em quadrinhos e cartuns objetivando compreender seu significado, possiveis intencionalidades para sua veiculação, bem como os valores atribuidos a esse material (MINAYO, 1999 p. 21). Ao mesmo tempo, procurou-se destacar a contribuição social dos quadrinhos para a divulgação de informações de saúde, uma vez que esses recursos, formatados na associação de desenhos caricaturais e pouco texto, são majoritariamente empregados em jornais e revistas de circulação popular, destinados a um público amplo, composto por crianças, adolescentes e jovens, como também de adultos.

Um projeto editorial no qual se utilize o recurso de veiculação de quadrinhos carrega intrinsecamente o apelo de uma destinação popular. Daí o interesse em se discutir o emprego desses recursos tendo em vista os propósitos de popularização da ciência no geral e particularmente das informações de saúde.

Cabe ressaltar que na história das histórias em quadrinhos, Klawa e Cohen (1970), relembram que “... é necessário que a história em quadrinhos seja entendida como um produto típico da cultura de massa ou especificamente da cultura jornalística." (KLAWA, COHEN, 1970, p. 108).

As histórias em quadrinhos utilizadas como um meio de comunicação, têm suas origens ligadas às empresas jornalísticas norte-americanas no final do século $X I X$, quando eram inseridas nos jornais com o propósito de aumentar a circulação, e consequentemente aumentar o número de vendas dos mesmos. Portanto, remonta à sua origem, uma importante característica que é a de comunicação de massa (LUYTEN, 1987)

O livro organizado por Vergueiro e Ramos (2009), Muito além dos quadrinhos: análises e reflexões sobre a $9^{a}$ arte, forneceu o subsídio inicial para a confirmação de que o recurso dos quadrinhos pode ser utilizado com a finalidade de transmissão de informações e não apenas como forma de entretenimento e diversão. Nesse livro pode-se constatar que os quadrinhos não são mais 
considerados como paraleitura ou subarte e que tratar dessa temática pelo viés científico, é a culminância desse reconhecimento.

O capitulo, "Quadrinhos e educação popular no Brasil: considerações à luz de algumas produções nacionais", assinado por Vergueiro, apresenta os resultados da análise de publicações que utilizam a linguagem quadrinística para a veiculação de conteúdos e transmissão de saberes específicos. O capitulo revela que essa utilização não é recente, mas sim que é pouco visivel e que há um desconhecimento da produção quadrinística voltada para a educação popular, por se tratar em geral de produções fora do circuito comercial. Dentre os saberes especificos tratados nesse capitulo, destacamos a menção à transmissão de informações de saúde.

Com relação à literatura consultada na base de dados PubMed, destacam-se seis artigos, aqui sucintamente abordados.

No artigo sobre artrite e reumatismo, que relata o estudo realizado por Moll et al (1977), constata-se que não houve diferenças significativas em dois grupos de pacientes testados quanto a informações transmitidas em folhetos com e sem cartuns, embora o material acompanhado de ilustrações tenha alcançado um score maior em algumas questões. Os autores se declararam surpresos com o resultado pelo fato de que naquela época já se reconhecia o valor desse tipo de recurso tanto no meio jornalístico, como nas propagandas, entretenimento e inclusive no uso educacional como aquele empregado naquela proposta especifica.

Os autores mencionam que a opção de leiaute das páginas da cartilha ilustrada com inclusão de até quatro cartuns em algumas páginas poderia explicar essa não diferença de resultados. Contudo, não apresentam o número de páginas de ambas as cartilhas; no entanto, o fato de explicarem que a cartilha ilustrada continha 89 cartuns, indica que ambas eram compostas por muitas páginas, o que não é adequado para um material educativo.

Por outro lado, Duffy e Burton (2000) relatam que os resultados de um estudo realizado em 1995 com 500 estudantes de escolas públicas de Chicago com rótulos advertindo os malefícios do tabaco, sem e com cartuns, apontaram que aqueles com cartuns recebem maior credibilidade do que os sem cartuns, permitindo-Ihes concluir que rótulos com cartuns são efetivos para alcançar crianças e adolescentes em campanhas antitabagismo. 
Embora a literatura consultada da base de dados PubMed demonstre a apropriação do recurso dos quadrinhos para a transmissão de informações do campo da saúde, ela também revela um uso inadequado, como na crítica que é feita por Fox (2006) à escolha pelo, National Heart, Lung, and Blood Institute (NHLBI), dos Estados Unidos, do gato Garfield como promotor de um comportamento saudável quanto às horas necessárias de sono para crianças em idade escolar.

Fox, conquanto reconheça o valor da proposta da campanha do NHLBI, apresenta uma série de comportamentos de riscos à saúde do gato Garfield, que é obeso, sedentário, e com chances de desenvolver problemas cardíacos e diabetes melitus. Dessa forma, explica o autor, Garfield, embora muito popular, não é um modelo apropriado para a promoção de saúde, mesmo porque até mesmo os hábitos de sono do famoso gato são questionados, por serem patológicos e não saudáveis.

Outra contribuição da PubMed, utilizando, contudo, outra conduta de busca que não o MeSH Terms, foi um ensaio discorrendo acerca do início da publicação nos Estados Unidos do mangá japonês Black Jack, intitulado "Mangás médicos chegam à América". Os mangás correspondem à versão japonesa das histórias em quadrinhos, que têm Osamu Tesuka (1928-1989) como um dos mais importantes autores. Tesuka, médico de formação, estudou medicina objetivando obter meios para praticar o que realmente Ihe interessava, que eram os mangás (Ishii, 2009, p. 542).

Destacamos esse ensaio assinado por Ishii (2009) pelo fato de ter sido publicado no conceituado periódico Canadian Medicine Association Journal, bem como pelo fato de apontar para uma publicação quadrinística composta por 17 volumes de aproximadamente 300 páginas cada, dedicado especificamente ao tema medicina. O objetivo desses mangás é o entretenimento, mas Ishii aponta, por exemplo, para questões éticas inseridas nos enredos.

Os quadrinhos veiculados no Jornal da Paulista, embora utilizassem o recurso do imaginário fantástico, não tratavam de assuntos ficcionais e por sua vez foram publicados em um jornal de uma universidade que no período de publicação do mesmo tinha na faculdade de medicina sua principal referência institucional e acadêmica.

Com relação aos artigos indexados na base de dados SciELO, que abordam o tema quadrinhos, destacamos o documento que relata a experiência do projeto desenvolvido pela "Oficina de Educação Através de Histórias em quadrinhos e 
Tirinhas (Eduhq)" do Centro Brasileiro de Pesquisas Físicas em parceria com a Fiocruz (CARUSO, SILVEIRA, 2009).

O projeto Eduhq foi estabelecido com o propósito de trabalhar conceitos de ciências, saúde, história, sociologia, linguagem, entre outros, com jovens de escolas públicas de ensino médio do Rio de Janeiro, utilizando o recurso de produção de histórias em quadrinhos. Objetivando também contribuir para o resgate da autoestima dos estudantes, e promover ainda motivação nos estudos, intercambiando ao processo criativo a valorização do espírito crítico e construção da cidadania.

Outro artigo recuperado da Base de Dados SciELO, trata especificamente da relação quadrinhos-saúde e foi escrito por Oliveira (2008). Apresenta os resultados da análise que a autora fez das cartilhas do projeto desenvolvido em 2005 pelo Ministério do Desenvolvimento Social e Combate à Fome (MDS), Criança saudável - educação $d e z$, ilustradas com histórias em quadrinhos e utilizadas para promover a educação nutricional de escolares das séries iniciais do ensino fundamental de escolas públicas.

A autora inicia suas considerações ressaltando o emprego positivo das histórias em quadrinhos como ferramentas pedagógicas, com potencial para transmitir mensagens, como motivadoras dos estudantes e como objetos de intermediação para abordagem de conceitos e disciplinas complexas e difíceis. $\mathrm{Na}$ conclusão de sua análise, Oliveira aponta para a possibilidade das cartilhas constituírem importantes instrumentos para sensibilizar tanto alunos como professores para tema como alimentação e nutrição; contudo, relata também que foram encontradas algumas inconsistências nas cartilhas que analisou, as quais, segundo suas conclusões, não comprometem o projeto do MDS.

No que diz respeito especificamente às questões de saúde, Oliveira destaca que as cartilhas apresentavam erros conceituais e históricos relacionados à alimentação e nutrição. Pode-se, no entanto, conjecturar se esse comprometimento está diretamente relacionado ao enredo das histórias em quadrinhos e não implicitamente aos quadrinhos e que uma boa revisão científica resolveria a questão.

$\mathrm{Na}$ base de dados SciELO foi ainda possivel localizar um artigo recuperado sob o termo cartum, no qual se discute teoricamente, apoiando-se em análise semiótica, os cartuns inscritos na "I Bienal Internacional do humor - sem Aids com amor", que ocorreu na cidade de São Paulo em 1997. A partir da definição de que 
cartum, segundo o Dicionário de comunicação de Rabaça e Barbosa (1987) ${ }^{3}$ "consiste numa anedota gráfica", Xavier (2001) defende que o "cartum clássico compõe-se de um jogo visual de ideias contido numa única ilustração, sem a presença de qualquer texto escrito", afirmando que o cartum difere de uma charge pelo fato de "que, enquanto o primeiro se utiliza de ideias gerais, universais e atemporais para realizar seu 'trocadilho visual', a segunda está sempre fundamentada num fato e momento histórico e objetivo, como, por exemplo, um acontecimento político" (p. 196).

A temática Aids também foi abordado no Jornal da Paulista, nas histórias em quadrinhos apresentadas na próxima seção, para ilustrar a veiculação de quadrinhos naquele jornal. Ressaltamos que este artigo não objetivou tratar teoricamente o conteúdo dos quadrinhos, como o fez Xavier.

\section{4 - Exemplos e sucinta análise do conteúdo das tiras em quadrinhos e cartuns veiculados pelo Jornal da Paulista}

O foco da proposição deste artigo não foi o de uma extensiva análise do conteúdo de histórias em quadrinhos e cartuns, pois isto demandaria uma publicação especifica. Lembrando que o propósito é a discussão da possibilidade do uso desses recursos para a transmissão de informações no geral e particularmente informações do campo da saúde, discorremos sucintamente sobre três tipos de tiras em quadrinhos e dois modelos de cartuns publicados no Jornal da Paulista. Com isto objetiva-se exemplificar o tipo de informação veiculado naquele jornal universitário, no formato de quadrinhos.

Deve-se salientar, ainda, que uma história em quadrinhos tem, obrigatoriamente, sempre um desenho, mas pode ou não ser acompanhada de balões de diálogo, ou de outro tipo de texto. Nesse sentido, pode-se dizer que o enredo de todas as tiras publicadas utilizava esse recurso híbrido $e$ isto proporcionava uma fácil leitura e compreensão.

A primeira tira em quadrinhos analisada (figura 2) foi veiculada na edição número 22 do jornal, publicada no mês de agosto de 1989, e abordou o tema insônia. Ela pode ser vista como um modelo daquelas com abordagem indireta ao

${ }^{3}$ RABAÇA, C. A.; BARBOSA, G. G. Dicionário de comunicação. São Paulo: Ática, 1987. 
tema saúde. Nessa tira, o profissional médico é retratado de forma estereotipada e adota uma conduta heterodoxa.

Figura 2 - Tira em quadrinhos sobre o tema insônia

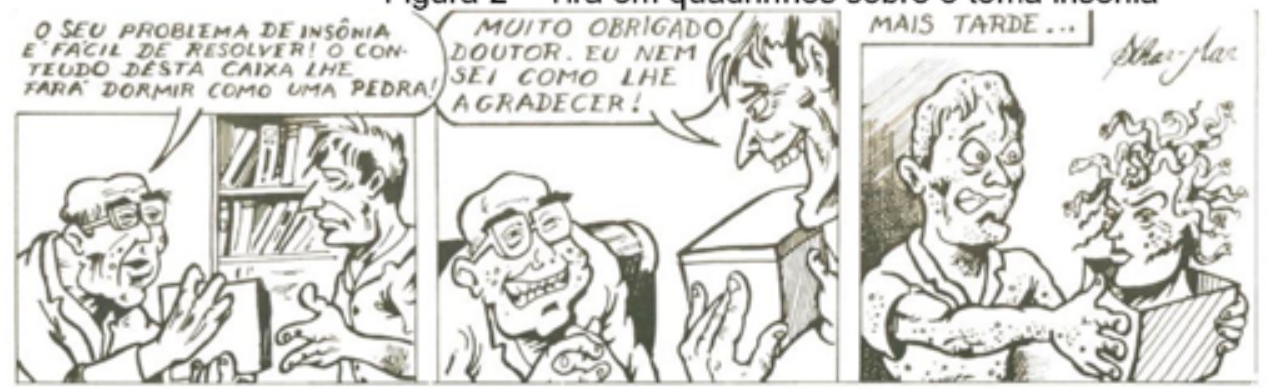

Fonte: Acervo do autor

Nos quadrinhos, quer no formato de cartum ou de tiras, há liberdade para se misturar elementos reais aos do âmbito do mundo mágico, mítico ou imagético. $\mathrm{A}$ tira em questão recorre ao mito grego da Medusa, que petrifica com seu olhar o incauto, para apresentar um problema de saúde real, no caso a insônia. A sátira está por conta do terceiro quadro, que remete ao primeiro e à fala do médico, segundo o qual sua prescrição faria o paciente "dormir como uma pedra".

O tema colesterol foi tratado na tira em quadrinhos "Hora do Recreio" (figura 3), veiculada na edição do Jornal da Paulista número 24 , publicada no mês de outubro de 1989. Nem todas as tiras publicadas no Jornal da Paulista receberam essa rubrica; contudo, é possível pressupor-se que isto revele o propósito de descontração que o autor tinha em mente tanto para as tiras quanto para os cartuns que publicou no jornal.

Figura 3 - Tira enfocando o tema colesterol

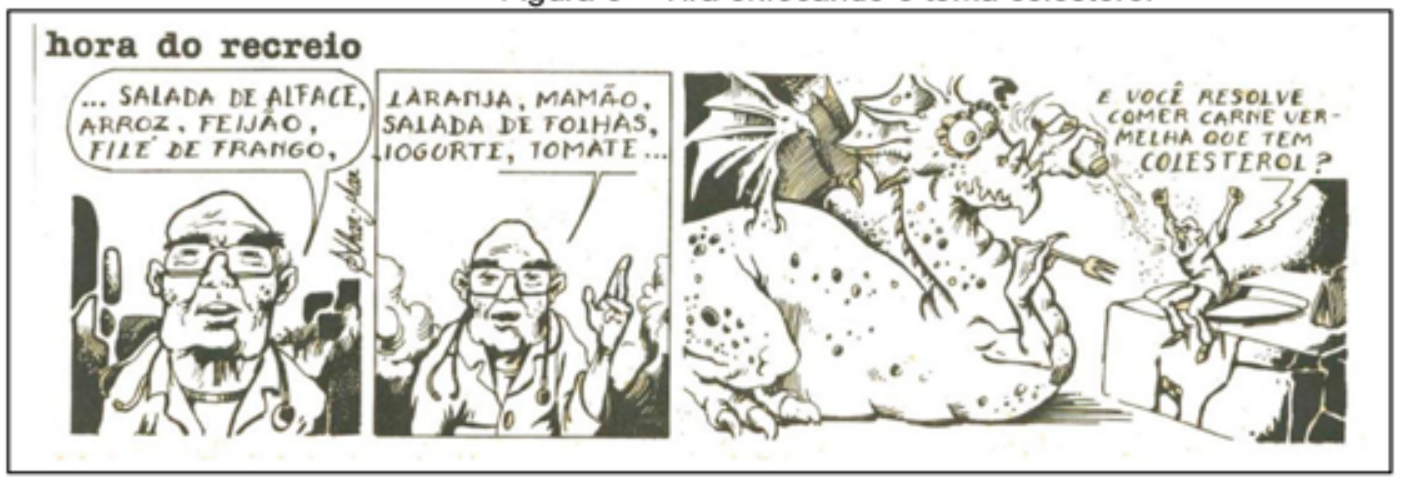

Fonte: Acervo do autor. 
O dicionário Aurélio (aplicativo para dispositivo móveis) explica o verbete recreio como "divertimento e prazer". Outros usos das tiras e cartuns publicados no Jornal da Paulista, que não este, é uma inferência de possibilidades acerca das quais se discutiu neste artigo. Embora o propósito recreação esteja explicitado na legenda, o tema saúde, nessa segunda tira, é tratado de forma muito mais direta do que aquela utilizada na tira anterior. Existe, na segunda, a nomeação de alimentos saudáveis listados nos dois primeiros quadrinhos, e a informação, no terceiro e último quadrinho, de que carne vermelha contém colesterol.

O protagonista desta tira, o mesmo personagem médico da figura 2 , é retratado nos dois primeiros quadrinhos com um ar professoral, como se estivesse ministrando uma aula ou palestra. O elemento lúdico da tira está no último quadrinho, que conclui o enredo da piada: o médico, prestes a ser devorado por um dragão, tenta convencer seu predador a optar por alimentos mais saudáveis.

Embora não se possa afirmar com certeza a intencionalidade do cartunista em tratar de forma lúdica os temas de saúde ou de transmitir informações de saúde, sua declaração ao jomal, apresentada na introdução deste artigo parece indicar as duas possibilidades.

A tira em quadrinhos publicada na edição do Jornal da Paulista número 25 (figura 4), que circulou no mês de novembro de 1989, sob a legenda "Seção Lavação" abordou o tema higiene. Nota-se que ela associa o emprego dos tradicionais balões de diálogo dos quadrinhos a pequenas caixas de textos contendo informações adicionais ao enredo da tira. No caso dessa figura, as caixas de textos contêm explicações sobre o beneficio do banho e sobre a melhor opção por sabonete de glicerina; assim, mais uma vez, o autor associa a ludicidade à transmissão de informação. Os protagonistas não pertencem ao mundo da magia, mas são caricaturas de pessoas comuns. 
Figura 3 - Tira enfocando o tema higiene
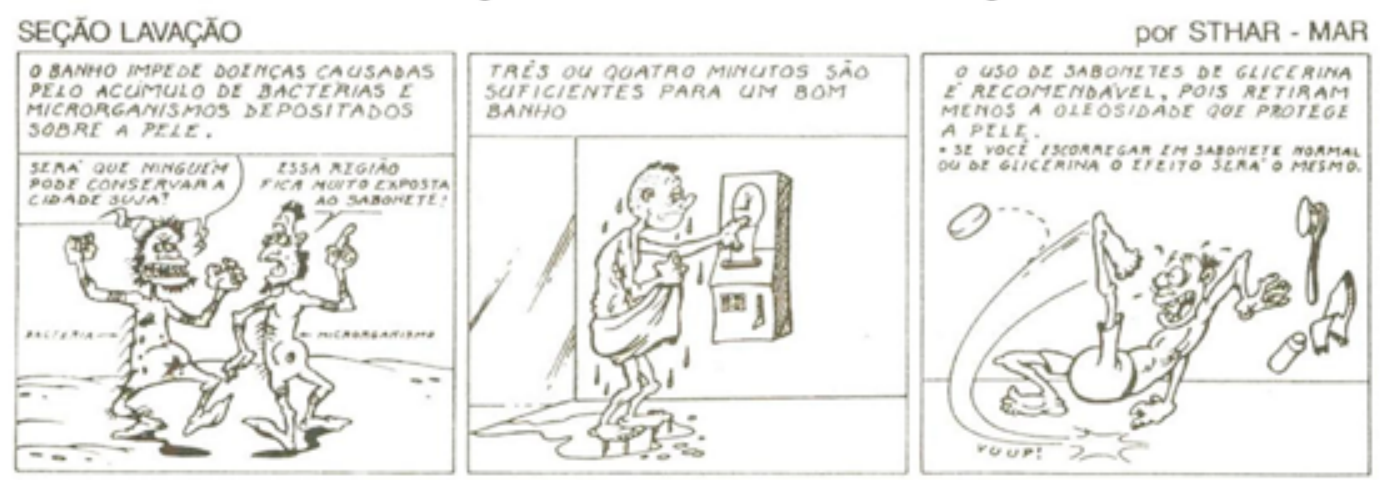

Fonte: Acervo do autor

Como mencionado anteriormente, o Jornal da Paulista publicou quadrinhos em formato de tiras e em cartuns. Para ilustrar o uso destes últimos, dois exemplos são discutidos a seguir. Ambos são compostos de desenhos acompanhados de balões de diálogo.

Na figura 5, temos um cartum publicado sob a legenda de "Seção Vibrião", que trouxe informação sobre o cólera e foi veiculado na edição do Jornal da Paulista n. 43, de maio de 1991. Nem todo balão de diálogo é necessariamente circundado por uma linha visível, como pode ser constatado no cartum/quadrinho acerca do vibrião do cólera. Esse mesmo cartum inclui ainda uma pequena caixa de texto que explica o tema de saúde ao qual se reporta o desenho ilustrativo.

Figura 5 - Cartum sobre o cólera

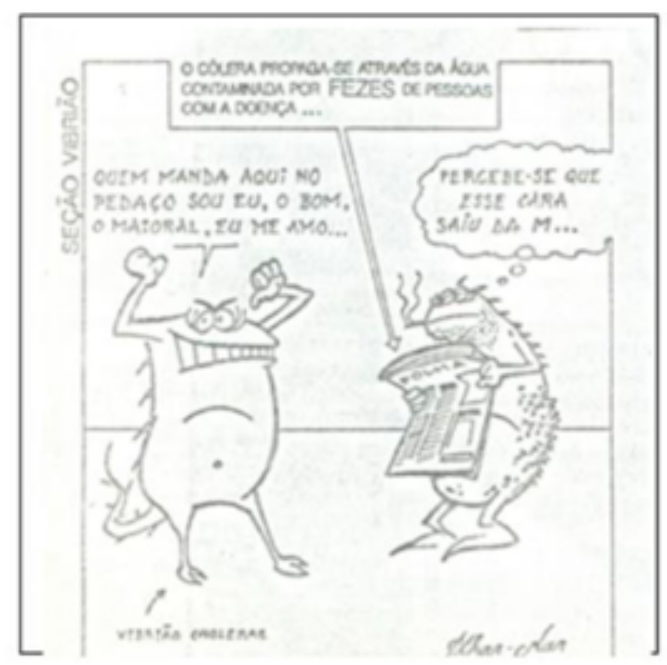

Fonte: Acervo do autor. 
A cirurgia plástica foi objeto do cartum (figura 6) publicado na edição do Jornal da Paulista n. 69, que circulou no mês de outubro de 1993:

Figura 6 - Cartum enfocando o tema cirurgia plástica

$$
\begin{gathered}
\text { Cirurgia Plástica } \\
\text { pode garantir a beleza } \\
\text { dos seios }
\end{gathered}
$$

Foi-se o tempo que ter seios imensos, era sinônimo de beleza...

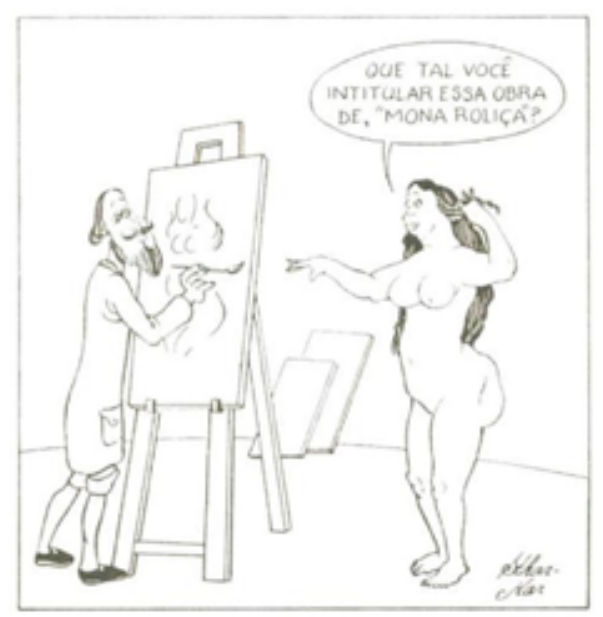

Fonte: Acervo do autor

Neste segundo cartum, o tema saúde perpassa pela complementaridade entre elementos textuais, duas frases localizadas fora dos quadrinhos e o elemento ilustrativo dentro do quadrinho, uma sátira à obra de arte Monalisa de Michelângelo. Inferências dentro do escopo sócio-cultural implícito nos quadrinhos - como, por exemplo, a representação da relação médico-paciente e o padrão estético cultural de corpo ideal -, são aqui apenas citados como exemplo de outra possibilidade de leitura de tiras e cartuns, que mereceriam ser aprofundados em outra pesquisa.

\section{Conclusão}

Ao longo das considerações anteriormente apresentadas, pode-se perceber a viabilidade da utilização dos quadrinhos, em suas vertentes de tiras em quadrinhos e cartuns para a divulgação de informação em saúde. Se, no passado, esse tipo de 
material era considerado como marginal, nas atuais sociedades do conhecimento seu emprego pode representar um canal para a divulgação de informações científicas e, ao mesmo tempo, uma contribuição para o processo de democratização e de acessibilidade ao conhecimento em geral, ao científico em particular, e em saúde, especificamente.

O estudo dos quadrinhos veiculados no Jornal da Paulista serviu como base para a constatação, como observado neste artigo de que o campo da saúde tem se apropriado desse recurso informacional. Como é imprescindivel que qualquer informação em saúde seja transmitida absolutamente de forma correta, as considerações que apontaram para equívocos na utilização da linguagem dos quadrinhos para esse tipo de divulgação de informação servem, sobretudo, como alerta para que tal uso seja feito sempre com a certeza de que a informação transmitida passe pelo crivo de especialistas, para não se incorrer no risco de prejuizo ao leitor.

Pelo número relativamente pequeno de documentos recuperados na base de dados SciELO fica a dúvida se a apropriação de quadrinhos pelo campo da saúde no Brasil é pouco explorada, ou se é pouco explorada a discussão acerca dessa apropriação por pesquisadores das histórias em quadrinhos. Resta, contudo, e para encerrar, a certeza de que os quadrinhos constituem, sim, ferramentas apropriadas para a divulgação de informações em saúde em específico, bem como para a divulgação de ciência no geral.

\section{Referências}

AMERICAN Heritage Dictionary of the English Language. 4.ed. New York, NY: Houghton Mifflin Company. 2000. Disponivel em: https://ahdictionary.com/. Acesso em: 13 abr. 2019.

AURÉLIO. Dicionário Digital Aurélio da Língua Portuguesa. [Aplicativo para dispositivos móveis]

BRANDÃO, Daniel. A linguagem dos quadrinhos. In: RAYMUNDO NETTO; VERGUEIRO, Waldomiro (coord.). Curso quadrinhos em sala de aula: estratégias, instrumentos e aplicações. Fortaleza, CE: Fundação Demócrito Rocha, 2018.

CARUSO, Francisco; SILVEIRA, Cristina. Quadrinhos para a cidadania. História, Ciências, Saúde, Rio de Janeiro, v.16, n.1, p. 217-236, jan-mar. 2009. 
DUFFY, Sonia; BURTON, Dee. Cartoon characters as tobacco warning labels. Archive of Pediatrics and Adolescent Medicine, v. 154, n. 12, p. 1230-1236, Nov. 2000.

EISNER, Will. Quadrinhos e arte sequencial. São Paulo: Martins Fontes, 2010.

FOX, Mark D. Sleeping with the enemy: Garfield and the National Heart, Lung, and Blood Institute. Pediatrics, v. 118, n. 3, p. 1257-1258, Sept. 2006.

GIL, Antonio Carlos. Como elaborar projetos de pesquisa. São Paulo: Atlas, 2007.

GODOY, Arilda Schmidt. Pesquisa qualitativa: tipos fundamentais. Revista de Administração de Empresas, São Paulo, v. 35, n. 3, p. 20-29, mai/jun, 1995.

GUIMARÃES, Edgard. Estudos sobre história em quadrinhos. João Pessoa: Marca de Fantasia, 2010.

ISHII, Anne. Medical manga comes to America. Canadian Medical Association Journal, v. 180, n. 5, p. 542-543, March 2009.

JORNAL DA PAULISTA, São Paulo, Escola Paulista de Medicina, 1987-2003.

KLAWA, Leonte; COHEN, Haron. Os quadrinhos e a comunicação de massa. In: MOYA, Álvaro de. Shazam. São Paulo: Perspectiva, 1970, p. 103-124.

LAKATOS, Eva Maria; MARCONI, Marina de Andrade. Fundamentos de metodologia científica. São Paulo: Atlas. 2006.

LUYTEN, Sonia Maria Bibe. O que é história em quadrinhos. São Paulo: Brasiliense, 1987.

McCLOUD, Scott. Desvendando os quadrinhos. São Paulo: Editora Makron Books, 1995.

MAGALHÃES, Henrique. Humor em pilulas: a força criativa das tiras brasileiras. João Pessoa: Marca de Fantasia, 2006.

MINAYO, Maria Cecilia de Souza. (Org.) Pesquisa social: teoria, método e criatividade. 13. ed. Petrópolis: Vozes, 1999.

MOLL, J M; WRIGHT, V; JEFFREY, M R; GOODE, J D; HUMBERSTONE, P M. The cartoon in doctor-patient communication: further study of the Arthritis and Rheumatism Council handbook on gout. Annals of the Rheumatic Diseases, v. 36, n. 3, p. 225-231, Jun. 1977.

OLIVEIRA, Kathlenn Sousa. Avaliação do material didático do projeto "Criança saudável educação dez", ano 2005. Interface - Comunicação, Saúde e Educação, Botucatu, v.12, n.25, p.401-10, abr./jun. 2008.

PUCCINI, Rosana Florini; SAMPAIO, Lucia Oliveira. BATISTA, Nildo Alves Batista (org.) A formação médica na Unifesp: excelência e compromisso social. São Paulo: Editora Unifesp, 2008.

SILVA, Marcia Regina Barros da. O ensino médico em São Paulo e a criação da Escola Paulista de Medicina. História, Ciências, Saúde, Rio de Janeiro, Manguinhos, v. 8, n. 3, p. 541-566, 2001. 
TEIXEIRA, Carlos Antonio. O Jornal da Paulista: a configuração de um meio de divulgação universitária numa perspectiva histórica. Saúde e Sociedade, São Paulo, v. 18, n. 4, outnov. 2009.

VERGUEIRO, Waldomiro; RAMOS, Paulo (org.). Muito Além dos Quadrinhos: Análises e Reflexões sobre a 9 ${ }^{a}$ Arte. São Paulo: Devir, 2009.

XAVIER, Caco. Aids é coisa séria! - humor e saúde: análise dos cartuns inscritos na I Bienal Internacional de Humor, 1997. História, Ciências, Saúde, Rio de Janeiro, Manguinhos, v.8, n.1, p. 193-221, 2001. 